\title{
Living arrangements in sub-Saharan Africa between modernization and ethnicity
}

\author{
Giuseppe Gabrielli ${ }^{1}$, Anna Paterno ${ }^{2}$ \& Pietro Sacco ${ }^{3}$ \\ ${ }^{1}$ Department of Political Sciences, University of Napoli Federico II, \\ Via Rodino' 22a, 80133 Naples, Italy \\ ${ }^{2}$ Department of Political Sciences, University of Bari, Piazza C. Battisti, \\ 1, 70121 Bari, Italy \\ ${ }^{3}$ Department of Economy and Finance, University of Bari, Largo Abbazia \\ Santa Scolastica, 70124 Bari, Italy \\ Email: giuseppe.gabrielli@unina.it
}

\begin{abstract}
Context/Background: Sub-Saharan Africa is characterized by an extraordinary diversification of living arrangements. It is a debatable question whether these features are evolving alongside the deep economic and social changes observed in the past few decades. Despite numerous studies on family changes and their effects, very few analyses consider different ethnic and geographical contexts.

Data Source and Methods: The paper observe the interaction between modernization and cultural heritage in shaping living arrangements in 10 sub-Saharan countries and in 38 ethnic groups. A temporal perspective has been adopted, comparing two successive DHS carried out between 1990 and 2013 .

Stratifying by ethnic groups and rural/urban contexts, factor analysis and hierarchical classification analysis investigate how living arrangements combine with fertility levels and socio-economic characteristics.

Findings: The results support the large heterogeneity of living arrangements and the increase of new family forms, rather than the existence of a convergence process on a single nuclear family pattern. Ethnic background is confirmed a valid interpretative key, necessary to understand the cultural substrate in which the modernization factors brought by globalization act.

Conclusion: National governments should develop and implement family policies that can raise the wellbeing of the emerging family models. In particular, family policies should support households in providing care and economic, material, psychological and affective support for their members.
\end{abstract}

Keywords: Living arrangement, Household, Sub-Saharan Africa, Factor analysis, Cluster analysis.

\section{Introduction}

In sub-Saharan Africa, the phenomenology of living arrangements is of great interest owing to the extraordinary diversification and complexity of the traditional family patterns. Ancient traditions and cultures have produced family forms (e.g., no-nuclear household, extended household, co-residential or non-co-residential polygamy) that do not conform to 'western' categories and are difficult to capture through large-scale international surveys (Gage, 1997; Mberu, 2007).

The continuous socio-economic evolution process interacts with cultural contexts, introducing further elements of complexity and generating original dynamics that produce a variety of changes and novelties. In particular, the predominance of the enlarged family over the biological family is a feature that traditionally distinguishes the conception and the organization of the sub-Saharan African family. It is a debatable question whether these features are http://aps.journals.ac.za remaining stable over time or are evolving alongside the deep economic and social changes witnessed by sub-Saharan countries in the past few decades.

There is a growing body of literature on family transition in Africa; studies have been conducted on family changes (related to formation, size, structure, dissolution and living arrangements) and on their effects (Odimegwu et al., 2017; Banda et al., 2017). Despite numerous local studies, very few analyses on living arrangements in sub-Saharan Africa consider different ethnic and geographical contexts (Garenne, 2004; Garenne and Zwang, 2006; Odimegwu and Kekovole, 2014). The scarce empirical evidences, collected in different countries, appear to be controversial, as the conceptual and definitional differences undermine the full comparability of the main outcomes and do not provide clear patterns.

To fill the existing gaps in the literature, this paper aims to describe and synthesize the different living 
arrangements in sub-Saharan Africa. We provide a multi-faced picture of the existing situation using robust analyses (factorial and cluster analyses). We classified the most widespread household typologies and described the ethnic/territorial and temporal complexity of living arrangements.

Our objective presupposes the identification and description of the existing household patterns, trying to find a comprehensive synthesis (through a factorial approach) of different socio-demographic, cultural and behavioural characteristics (e.g., marriage, fertility, education, employment and religion) connected with these patterns. In this perspective, all the most widespread household typologies are considered, with the maximum detail, according to available data.

According to the territorial perspective, we compare 10 countries located in different regions of the continent. Within each national context, the analysis is stratified by 38 ethnic groups and rural/urban contexts to investigate how they resemble each other or differ with regard to these aspects.

The temporal perspective compares two Demographic and Health Surveys (DHS) carried out between 1990 and 2013.

In the next sections, after recalling the previous relevant literature useful to define the working hypotheses, the data and methods are introduced. The next two sections present the obtained descriptive results and multidimensional findings. Lastly, an attempt is made to synthesize and understand such results to provide an answer to the initial questions and to consider their interrelation with some socio-political issues.

\section{Literature review and theoretical framework}

Demographic investigations show that many changes are undoubtedly taking place in marriage and fertility patterns in sub-Saharan Africa (Bledsoe and Pison, 1997; Maffioli, 2003; Odimegwu and Kekovole, 2014). The predominance of matrilineal or patrilineal lineage, the enlarged family (defined as including members who are not part of the biological group mother-father-children, Laslett, 1972I) and its interests with respect to the biological family (parents and their children) are features that traditionally distinguish the conception and the organization of the family in this sub-continent (USAID, 2005; Bosede et al., 2017). Cultural systems and customs that developed in the framework of traditional religions and the particular economic arrangements that regulate family life are at the basis of these conceptions and organizations. Change in marriage patterns may be associated with cultural factors and socio-economic dynamics and/or with the characteristics of the marriage market (Caldwell and Caldwell, 1987; Garenne, 2004).

According to demographic transition theory (Notestein, 1953; Caldwell, 1976), we expect a process of familiar 'nuclearization', that is, a growing incidence of families formed by a single biological father-mother-children nucleus. More generally, an increased importance of the conjugal link with respect to other kinship ties is considered as an inevitable step in demographic transition, which is inextricably bound up with a profound alteration of the traditional cultures. In this view, the strengthening of the link between the spouses, both in terms of affection and in terms of common economic interests, is the prerequisite for the onset of fertility decline. It is the spouses' perception of building, together with the children, an independent unit that has sole responsibility for its own destiny that creates the conditions in which family planning acquires meaning (Nyauchi and Omedi, 2014).

However, many authors have questioned the existence of a simplistic process of change from a mythical society composed of extended households to a generalized nuclearization; conversely, they have stressed other ongoing processes experienced by the sub-Saharan African family, particularly the growth of no-nuclear and female-headed one-parent families (e.g., Locoh, 1995; Cordell and Piché, 1995). Other scholars have highlighted the persistence of strong kinship ties and of a solid network of rights and duties between members of the same lineage, over and above the structural transformations of household groups that may occur for contingent reasons (e.g., Adepoju and Mbugua, 1997; Maffioli et al., 2006).

In short, we support the 'systemic' approach, that is the most widely accepted theoretical framework, according to which the emergence of new rules of social life implies the diversification of living arrangements and the strengthening of new configurations rather than the convergence on a single nuclear family model (Vignikin, 1997).

Following this approach, scholars showed that different groups adopt different living arrangements. Among the determinants of these arrangements, a particular emphasis has been reserved to urban/rural and ethnic differences (Odimegwu et al., 2017).

As cultural and economic changes usually begin in towns, the rural/urban contrast has often been considered as a way of summarizing the impact of ongoing social changes. It was showed that urbanization has greatly contributed to shaping the different family patterns (Haiase and Liaw, 1997). In particular, urbanization has led to the decline in polygamy because of the high costs of living, shortages of houses, weakened kinship system and 
high risks of unemployment in urban areas (Odimegwu et al., 20I7).

Previous analyses highlighted that ethnic differences are another perspective for understanding the complexity of African living arrangements. Individuals' cultural attachments and identity may affect family formation and behaviours (Moore and Govender, 2013; Bosede et al., 2017). Ethnic groups are by definition culturally homogeneous aggregates of individuals having developed along their history their own social organization and family systems, and may thus be considered as a proxy for all the norms and ideals that traditionally govern living behaviours and arrangements (Eriksen, 1993; Sellier, 2003).

Bearing in mind this theoretical framework, this paper aims to answer the following question:

$\mathrm{HI}$ : Is a significant nuclearization process, expressed by a growing incidence of household biological nucleus, taking place in sub-Saharan Africa? Is this nuclearization part of an increasing diversification of living arrangements and of a strengthening of new family forms? $\mathrm{H} 2$ : Is there one living arrangement pattern that prevails among the others in the sub-Saharan countries? $\mathrm{H} 3$ : Is it possible to synthesize the variety of the living arrangements by ethnic groups according to linked socio-demographic, cultural and behavioural characteristics?

\section{Data and methods}

This analysis concerns different countries of subSaharan Africa, where at least two Demographic and Health Surveys (DHS) were carried out between 1990 and 2013. In particular, two subsequent editions of the survey, held in the following ten countries, were observed: Benin, Burkina Faso, Cameroon, Ethiopia, Ghana, Kenya, Mali, Mozambique, Nigeria, Zambia. This study stresses the differences existing in the urban and in the rural contexts. The selected countries differ from one another in historical experience, degree of economic and social development, and demographic conditions.

Moreover, this paper highlights the variability by selected ethnic groups for each country (in all, 38 ethnic groups, see figure I) in the distribution of the different categories of households. They cannot represent the whole sub-Saharan area, but they certainly provide an effective picture of the widely prevalent situation.

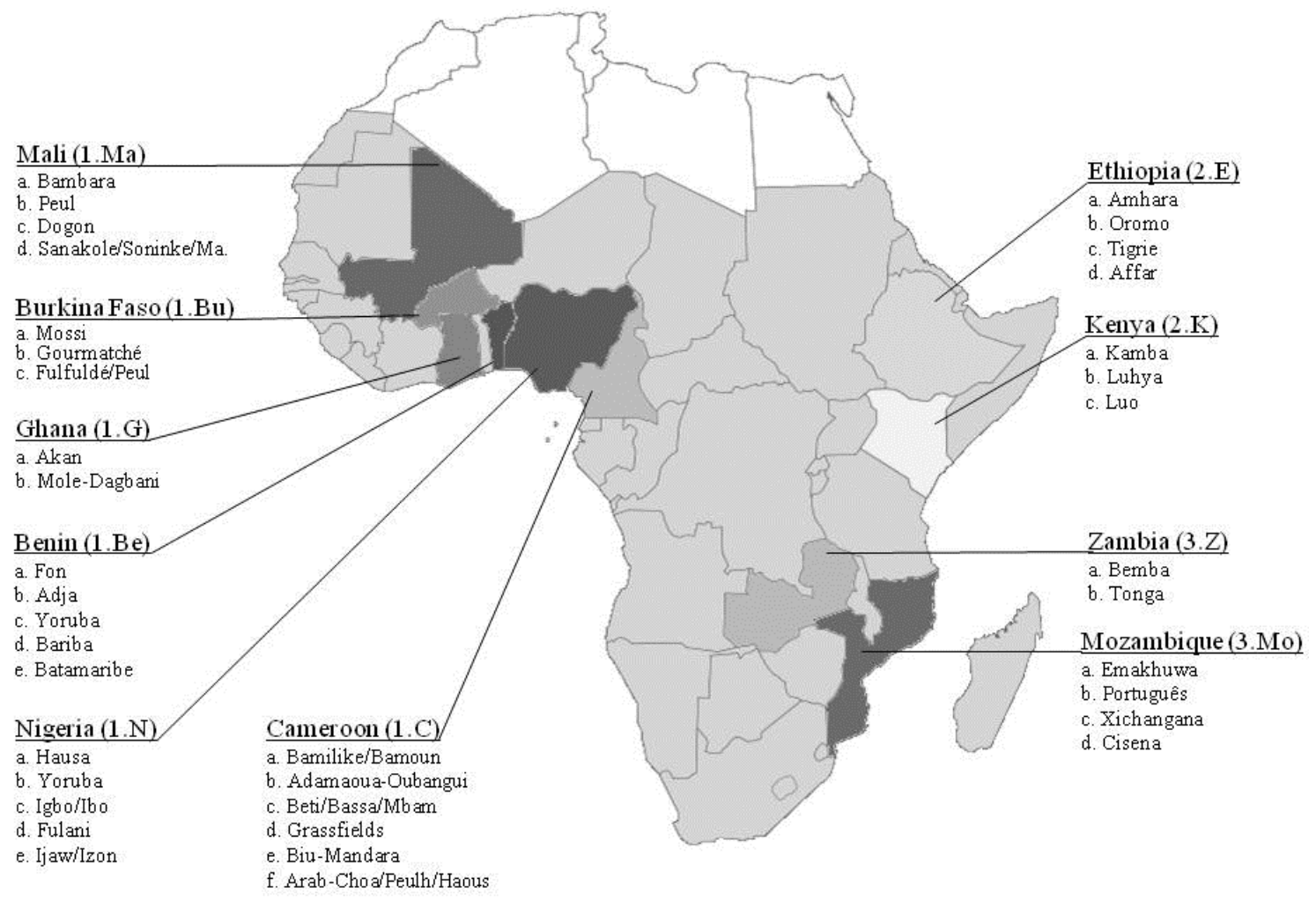

Note: I =Central-West African group; 2 =Central-East African group; 3 =South African group.

Figure I: Selected 38 ethnic groups in 10 sub-Saharan countries. 
Despite being designed for other purposes, the two editions of the DHS collected an extraordinary wealth of internationally comparable information about households, which offers possibilities to examine the living arrangements even in a temporal perspective. Used data permit the identification and a synthetic description of living arrangements, a description that can be considered an important goal in itself, since information on family and household structures in sub-Saharan Africa has previously been quite scarce.

Available information made it possible to construct a household classification loosely inspired by that proposed by Laslett (1972). DHS data refers to 'household' as 'co-resident domestic groups of related or non-related persons ... who acknowledge one adult male or female as the head of the household, who share the same housekeeping arrangements and are considered as one unit' (DHS, 1996: p. 48). Thus, this study's information does not allow any appraisal of the entire kinship network and the reciprocal rights and duties among its members. This is a very general problem, which hinders family studies everywhere in the world, but which may be especially serious in Africa, given the particular relevance of kinship ties. However, DHS data provide an evaluation of the degree of 'nuclearity' of the households. After defining the 'family nucleus' as a group of persons linked by a relationship of reproduction or a conjugal tie, all of the households that do not contain any family nucleus (singles, divorced or widowed individuals, persons living alone and co-resident related or not related persons) were classified as 'no-nuclear'. Two different categories have been related to the nuclear household: the oneparent household (one parent with offspring and eventually with other related or not related persons), the conjugal household, formed by a couple or a couple with offspring. The polygenic household is formed by a man and more than one wife with or without offspring. In the end, the extended household included the conjugal household with the addition of other related or not related persons. This household is horizontally extended and may or may not be multinuclear. Further insights concern the spread of the female-headed household and of polygynous wives, where the latter is the percentage, among the total respondent women, of women declaring that their husband also has other wives (with neither the husband nor the other wives necessarily living with the respondent woman).

The adopted typology is designed to stress the eventual polarization around simple conjugal families, and at the same time to witness the emergence/spreading of one-parent families, while considering polygamy an aspect of the permanence of the traditional pattern, with the hypothesis that it is based on extended households.

According to the previously described categories of household, this study first performed comparative and diachronic descriptive analyses across countries and within the same country to describe the processes of nuclearization in two subsequent survey years.

In order to investigate how the characteristics of living arrangements combine with the level of fertility and the degree of socio-economic development, and how countries and ethnic groups resemble one another or differ with regard to these aspects, this study applied to the most recent survey data the classical procedure of factor analysis with the principal components method (PCA), followed by an hierarchical classification analysis (cluster analysis).

In the initial matrix of the PCA, the 38 ethnic groups form the statistical units, which are described at macro-level by 28 elementary indicators: 12 are concerned with socio-cultural aspects, 5 with types of household, 6 with women's condition within/without the couple (highlighting their level of independence and empowerment) and 5 with union and fertility events (for a detailed list of indicators, see table 2).

The PCA estimates new synthetic variables (principal components) obtained by the linear combination of the original ones, so that they represent the widest possible portion of the total variability. The composition of synthetic indicators (factors or components), which takes simultaneous account of the correlations of all elementary indicators, facilitates the exploration of the associations among variables and also, thanks to suitable graphical representation, the collocation of the observed ethnic groups in relation to those variables on the factor plane. PCA allows us to define ethnic groups not with respect to the starting parameters, but on the basis of the principal components.

Based on the principal components emerging from the PCA, cluster analysis was performed using "Ward's method" which creates partitions that ensure the minimum intraclass and maximum interclass variability (Ward, 1963; de Amorim, 2015). Ward suggested a general agglomerative hierarchical clustering procedure: at each step, it leads to minimum increase in total within-cluster variance after merging. This increase is a weighted squared distance between cluster centers. With hierarchical clustering, the sum of squares starts out at zero and then grows as clusters are merged. Ward's method keeps this growth as small as possible. Obviously, in this type of analysis, the greater is the level of aggregation (with a lesser number of groups

http://aps.journals.ac.za 
individuated) the greater is the level of variability observed within each group.

The partition in six clusters, obtained by using a Ward method, seems to be the best way to obtain a clear and synthetic schematization of the varied panorama of the family patterns in sub-Saharan ethnic groups. Though oversimplified, the picture that can be drawn has the advantage of defining typical living arrangements and of clearly illustrating (or reasserting) some particular aspects.

\section{Results}

Obtained results in table I show firstly that, in both DHS waves, the conjugal household is the most widespread family typology, both in all the rural contexts of the ten observed countries and in six urban contexts. In particular, such household category ranges, in the most recent wave of the DHS survey, from $57.8 \%$ of Ethiopia to $30.5 \%$ of Cameroon in rural areas, and from $49.6 \%$ of Nigeria to just $26.2 \%$ of Mozambique in urban areas.

Ghana and Kenya display high percentages of oneparent and no-nuclear households. Ethiopia and Zambia are distinguished by a prevalence of the nonuclear category, but in Zambia there are also many extended households. Lastly, Mozambique combines significant levels of one-parent households with a significant number of extended families.

The polygenic households (both in rural and in urban areas) are much more present in Burkina Faso, Mali, Nigeria and Cameroon than other countries.

The extended households (thus, conjugal households with the addition of other related or not related persons) are the most common model in urban areas of Burkina Faso, Cameroon, Zambia and Mozambique in both DHS waves (plus Benin and Ethiopia in the first wave).

The differences between urban and rural families are marked in all countries, but they differ in sign and meaning: one-parent, conjugal and polygenic households are more frequent in the rural contexts, except in the case of Nigeria; no-nuclear, one-parent and other extended households are more frequent in the urban contexts.

Some ideas of the ongoing changes can also be drawn from the diachronic data, observing the differences among the results referring to each of the two waves of the DHS survey and neglecting that a time span of 20 years, at best, between two successive observations is probably not enough to assess with certainty the long term evolutions. The exploitation of our data highlights that, in the period between the two considered surveys, the proportion of conjugal households grew in all of the ten urban and in eight rural national contexts. At the same time, the extended households generally declined, except in Ghana and Kenya (plus urban areas in Mali and Burkina Faso, and the rural context of Cameroon). The polygenic households reduced in all considered countries, with the exceptions of Mali, Burkina Faso, Ghana and Benin (plus the rural context of Nigeria and Cameroon). Conversely, while the one-parent model increased in all of the considered countries (saving Mali and Ethiopia), the no-nuclear model reduced everywhere (saving Mozambique).

Another interesting indicator is represented by the frequency of female-headed households. The increase of such household typology is much more evident in the urban context (and in particular in Cameroon, Kenya, Zambia and Mozambique) than in the rural one.

In contrast, the percentage of so-called 'polygynous wives' (as to say, the women declaring that their husband also has other wives) among total respondents declined in all of the countries between the two waves, mostly in the countries where it was more widespread (Mali, Benin, Nigeria, Cameroon in both contexts and Burkina Faso and Ghana in rural areas).

Table I: Distribution of the household classification by rural/urban residence and two different years in ten sub-Saharan countries. Percentage values.

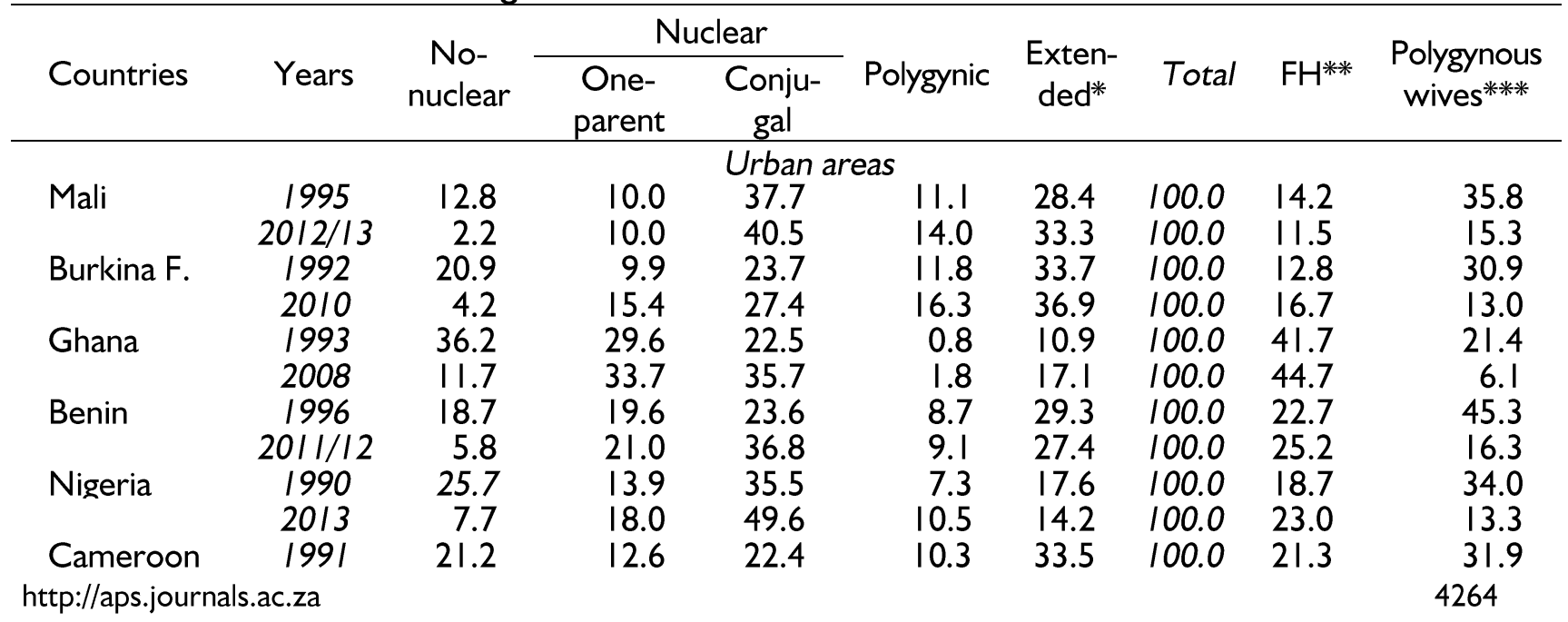




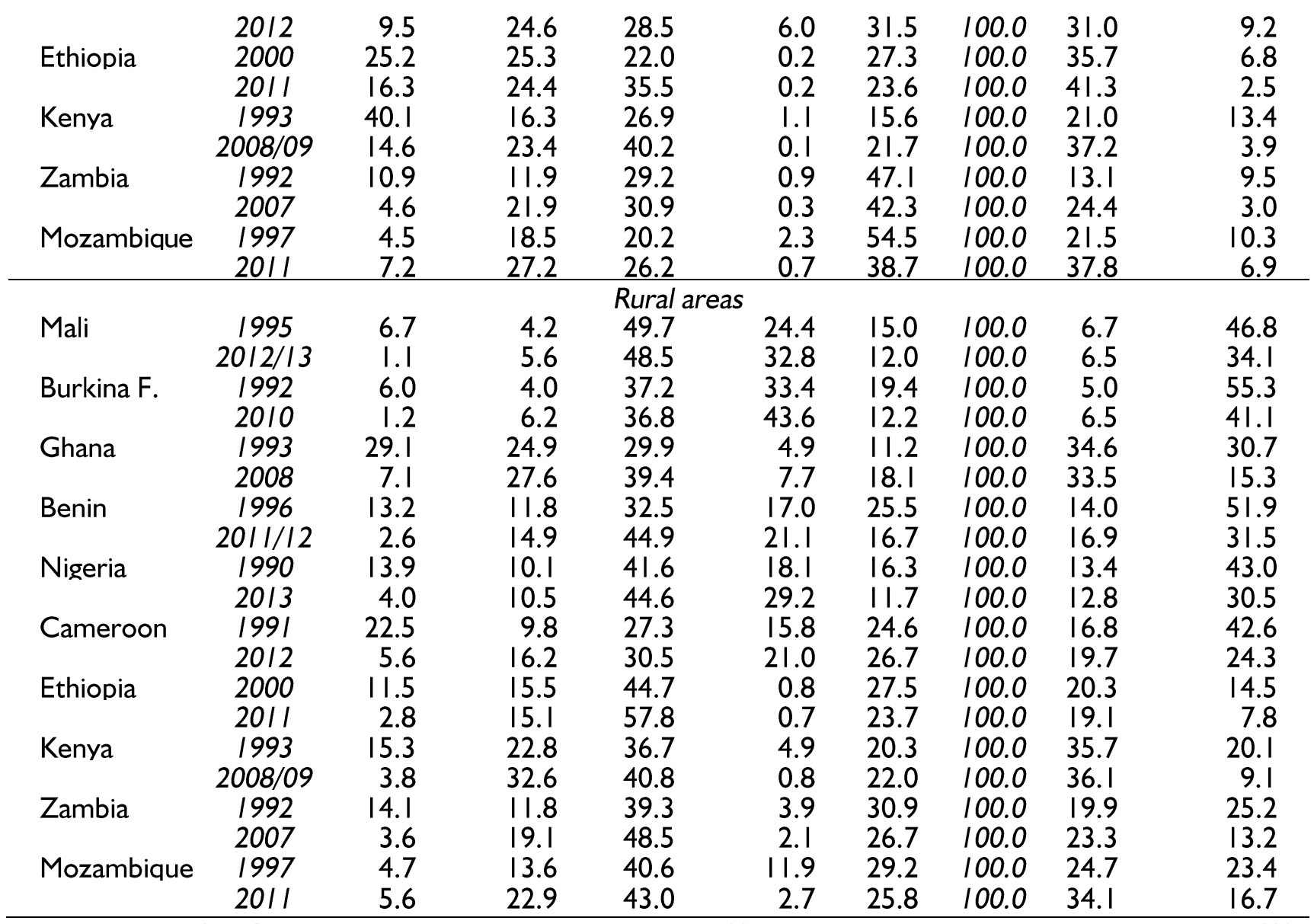

Notes: Extended $*$ Conjugal household plus other members; $\mathrm{FH}^{* *}=$ Female-headed household; Polygynous wives*** $=$ percentage of women declaring that their husband has also other wives on the total respondent women (nor the husband or the other wives are necessarily living with the respondent woman).

Confining this analysis to the last observed year in each country, an enormous variability by ethnic group is highlighted (figure 2). Generally speaking, the left side of the diagram shows the ethnicities with the largest quotas of extended households; the right side shows the ones with the largest amounts of oneparent households.

The proportion of women in conjugal households varies between the 19\% of the Beti (Cameroon) and the $57 \%$ of the Oromo (Ethiopia). Those in oneparent households range from the $3 \%$ of the Gourmatché (Burkina Faso) to the 39\% of the Português (Mozambique). The percentage of polygynic households is $0 \%$ among the Affar and Tigrie (Ethiopia) and 46\% among the Gourmatché. Yoruba and Peulh ethnicities are present in different countries but, interestingly, present similar distributions of households.

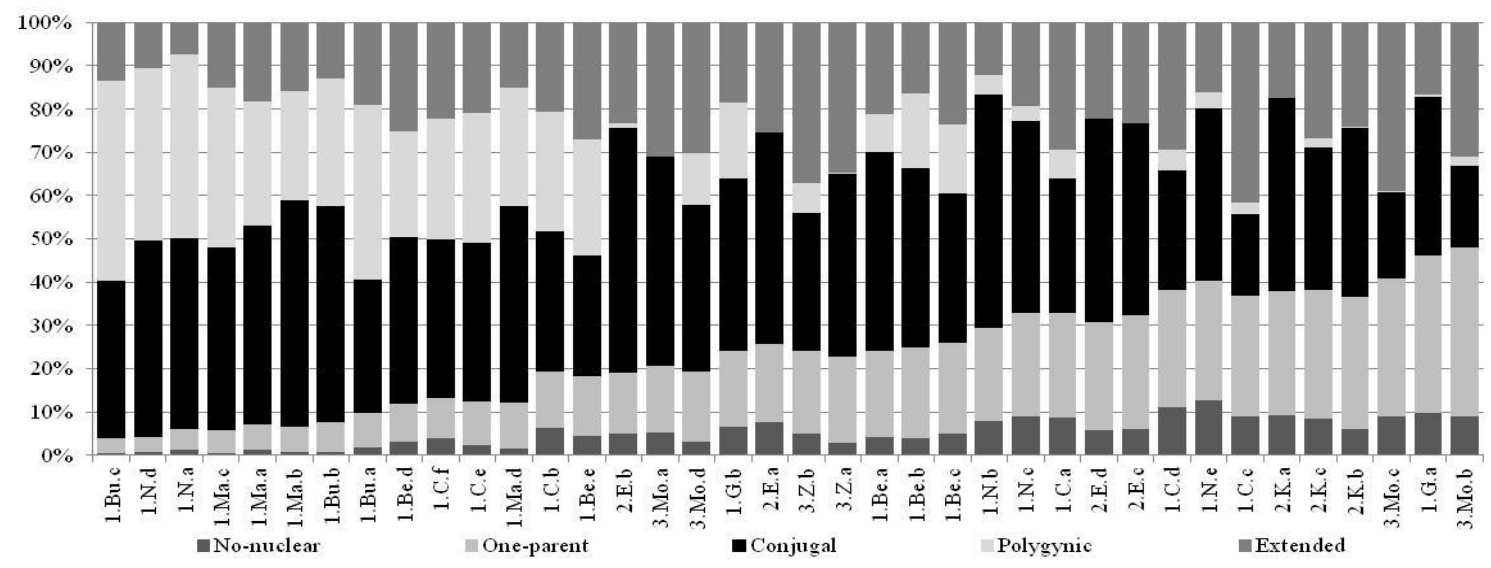

Note: see figure I for the full explanation of ethnicity/country achromous.

Figure 2: Distribution of the household classification in the main ethnic groups of ten sub-Saharan countries and in the last observed year. Percentage values. 
The results obtained through the application of the factor analysis with the principal components method (table 2) permit consideration of the three principal components with an auto-value greater than one, which explain $67 \%$ of the total variability.

Table 2: Correlations between the scores of the first three synthetic factors (with an autovalue greater than one) and the elementary indicators of the factor analysis with principal component method (Varimax rotation*).

\begin{tabular}{|c|c|c|c|c|c|}
\hline \multirow{2}{*}{ Characteristics } & \multirow{2}{*}{ Description of the elementary indicators } & \multirow{2}{*}{ Labels } & \multicolumn{3}{|c|}{ Factors } \\
\hline & & & I & 2 & 3 \\
\hline \multirow{12}{*}{$\begin{array}{l}\text { Socio-economic } \\
\text { and cultural aspects }\end{array}$} & $\%$ illiterate among men & ILLEDM & - & 0.4 & 0.1 \\
\hline & $\%$ illiterate among women & ILLEDF & - & 0.5 & 0.1 \\
\hline & $\%$ relative gender difference of illiteracy & DRGI & 0.1 & 0.5 & 0.1 \\
\hline & $\%$ men with high education & HIEDM & 0.3 & - & - \\
\hline & $\%$ women with high education & HIEDF & 0.2 & - & 0.0 \\
\hline & $\%$ relative gender difference in high & DRG2 & - & 0.4 & - \\
\hline & $\%$ urban population & URB & 0.3 & - & - \\
\hline & $\%$ working in agriculture & AGR & & 0.5 & 0.5 \\
\hline & $\%$ working in services and trade & TRAD & 0.0 & - & - \\
\hline & \% Muslims & MUSLIM & - & 0.2 & 0.1 \\
\hline & $\%$ Christians & CHRISTIA & 0.7 & - & 0.0 \\
\hline & $\%$ Animists & ANIMIST & 0.1 & 0.1 & - \\
\hline \multirow{5}{*}{ Types of household } & $\%$ no-nuclear households & NNUC & 0.6 & - & - \\
\hline & $\%$ one-Darent households & ONEP & 0.7 & _ & _ \\
\hline & $\%$ coniugal households & CONI & - & - & 0.7 \\
\hline & \% Dolygynic households & POL & - & 0.4 & - \\
\hline & $\%$ extended households & EXT & 0.7 & 0.1 & _ \\
\hline \multirow{6}{*}{$\begin{array}{l}\text { Women } \\
\text { within/without } \\
\text { the couple }\end{array}$} & $\%$ married women not living with & NCONV & 0.4 & - & - \\
\hline & $\%$ women married more than once & PLURF & 0.5 & 0.2 & 0.4 \\
\hline & $\%$ widowed & WIDOVE & 0.6 & - & - \\
\hline & $\%$ divorced women & DIVORCE & 0.4 & 0.2 & 0.7 \\
\hline & $\%$ households with female head (on total & $\mathrm{FH}$ & 0.8 & - & - \\
\hline & $\%$ of women among solitaries & FSOL & 0.4 & & 0.1 \\
\hline \multirow{7}{*}{$\begin{array}{l}\text { Marriage } \\
\text { fertility }\end{array}$} & $\%$ men married before age 25 & $M<25 M$ & 0.1 & 0.6 & 0.0 \\
\hline & $\%$ women married before age 20 & $M<20 F$ & - & 0.6 & 0.0 \\
\hline & Mean num. of children ever born to wom. & CEB2 & - & 0.8 & - \\
\hline & Mean num. of children ever born to wom. & CEB3 & - & 0.8 & - \\
\hline & Mean num. of children ever born to wom. & CEB4 & - & 0.7 & 0.1 \\
\hline & Autovalues & & 13. & 2.9 & 2.4 \\
\hline & $\begin{array}{l}\% \text { lotal variance } \\
\% \text { Cumulative total variance }\end{array}$ & & 47. & $\begin{array}{l}10 . \\
58 .\end{array}$ & $\begin{array}{l}8.9 \\
66 .\end{array}$ \\
\hline
\end{tabular}

Notes: *Varimax rotation was necessary to improve the interpretation.

The first factor, which absorbs almost half of the total variability $(47.5 \%)$, contrasts the polygenic households (negative correlation) with other extended, one-parent and no-nuclear households, as well as female-headed households (positive correlation). This factor is negatively associated with Islamic religion and illiteracy, while it is positively associated with Christian religion and high levels of independence and empowerment of the women within couples. These correlations do not necessarily imply a relation of causality but rather reflect an existing reality.

The second factor $(10.5 \%$ of the variability explained) contrasts the gender parity (negative correlation) with gender disparity (negative correlation). The parity is represented by high levels of education and urbanization, while the disparity corresponds to high levels of fertility, of early marriages and of agricultural workers, and a large imbalance of education by gender.

Lastly, the third factor explains $8.9 \%$ of the variability: there is positive correlation is with the percentage of conjugal households, and the negative correlation is with the spread of traditional religions (Animist).

The 38 examined ethnic groups are plotted on two factorial planes formed, respectively, by factors I and 2 (figure 3 ) and by factors I and 3 (figure 4). The considerable dispersion of the groups testifies to the wide variety of possible combinations of living arrangements and explicative factors and, thus, to the great ethnical heterogeneity in this respect. Analysing individually the position of each collectivity reveals 
how some of them are particularly distinct from the others for the same characteristics.

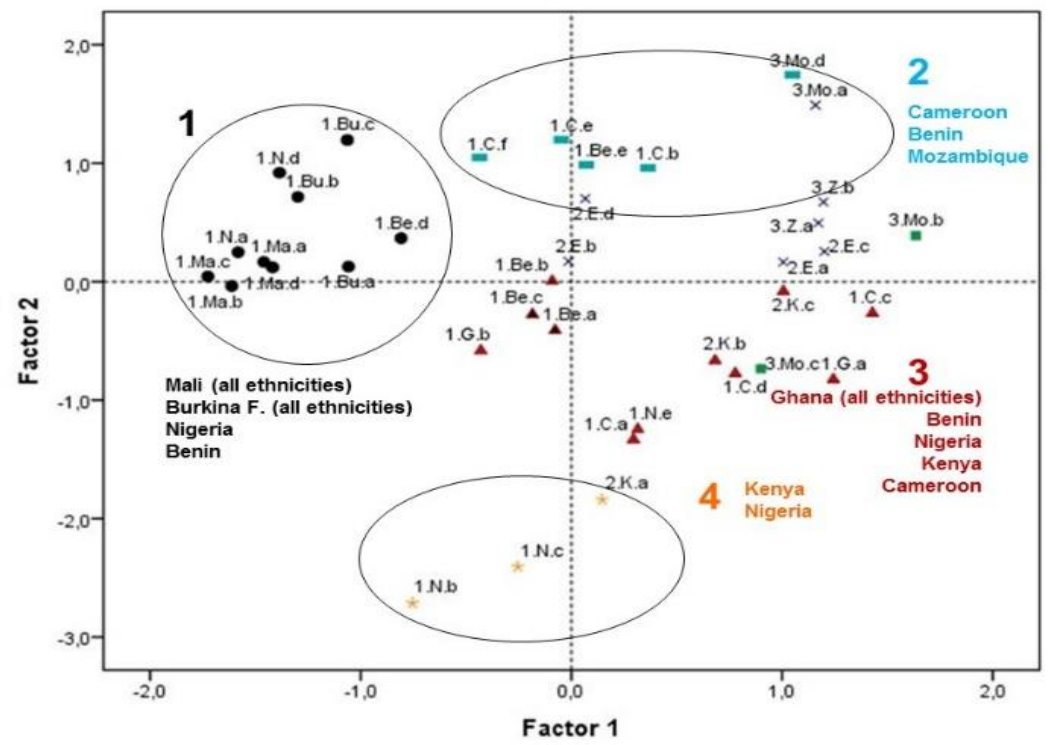

Note I: • cluster I; - cluster 2; $\Delta$ cluster 3; * cluster 4; $\mathbf{x}$ cluster 5; $\mathbf{\square}$ cluster 6

Note2: see figure I for the full explanation of ethnicity/country achromous.

Figure 3: Projections on the Cartesian axes of the three principal factors by 38 ethnic groups in 10 African countries and by six clusters.

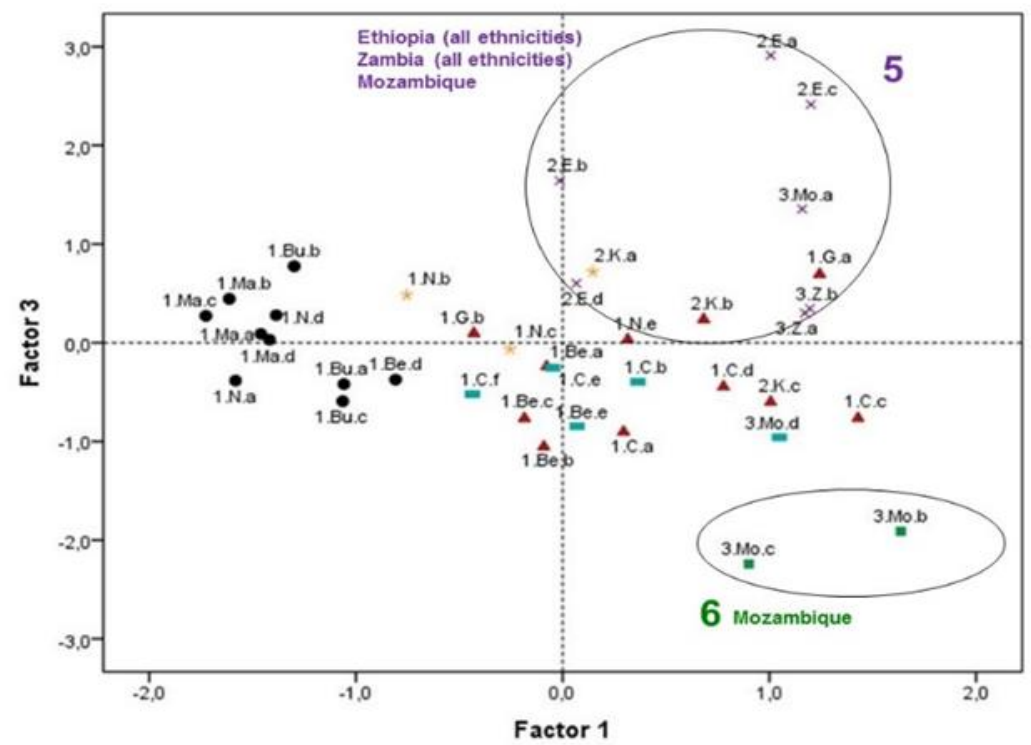

Notel: • cluster I; - cluster 2; $\Delta$ cluster 3; * cluster 4; x cluster 5; $\mathbf{\square}$ cluster 6

Note2: see figure I for the full explanation of ethnicity/country achromous.

Figure 4: Projections on the Cartesian axes of the three principal factors by 38 ethnic groups in 10 African countries and by six clusters.

To better interpret the associations among ethnic groups on the basis of similarity with respect to the variables considered, the information that can be deduced from the division performed by cluster analysis was employed. As previously specified, a partition with 6 clusters was chosen (table 3).

Cluster I includes ten ethnic groups (of four countries): all selected ethnic groups of Mali and Burkina Faso, Bariba (Benin) and Hausa and Fulani
(Nigeria). It is characterized mainly by the polygenic households, although a large percentage of conjugal households is also present. The ethnic groups included in this cluster also show the highest incidences of illiteracy for both genders (a limited percentage of people reaches high educational levels). The level of urbanization is the lowest, the fertility levels (CEB2, CEB3 and CEB4) reach the second highest values, and the percentage of women 
married before age 20 is high. This cluster is essentially Islamic (84.3\%).

Cluster 2 comprises five ethnic groups: Batamaribe (Benin); Adamaoua-Oubangui, BiuMandara and Arab-Choa/Peulh/Haous (Cameroon); and Cisena (Mozambique). It is characterized by a mixed pattern in a modern context, where oneparent households conjugal households and extended households are widespread. The degree of urbanization and the levels of socio-economic variables assume intermediate values, while the fertility levels and the proportions of early marriages are low.

The quota of households with a female head is high, and polygyny is not completely absent. The proportions of highly educated and illiterate people reach intermediate levels for both genders. This is the second group with the most widespread Christianity (80.7\%).

Cluster 3 has eleven ethnicities: all selected ethnic groups of Ghana; Fon, Adja and Yoruba (Benin); ljaw/Izon (Nigeria); Bamilike/Bamoun, Beti/Bassa/Mbam and Grassfields (Cameroon); and Luhya and Luo (Kenya). It represents a mixed pattern in a traditional context, with an equal partition between conjugal, polygynic and extended households. This cluster is also 'mixed' with reference to religion. The proportion of highly educated people reaches the lowest values among men and women, and the quota of illiterate people is high for both genders. The degree of urbanization is low, while the quota of people working in agriculture is elevated, as is fertility and the proportion of early marriages.

Table 3: Mean values of the elementary indicators in the six clusters outlined through the cluster analysis and using the three principal component factors.

\begin{tabular}{|c|c|c|c|c|c|c|c|}
\hline \multirow{2}{*}{ Variables } & \multicolumn{6}{|c|}{ Clusters } & \multirow{2}{*}{ Total } \\
\hline & 1 & 2 & 3 & 4 & 5 & 6 & \\
\hline ILLEDM & 82.2 & 20.1 & 47.7 & 5.1 & 39.0 & 7.3 & 41.7 \\
\hline ILLEDF & 80.8 & 22.6 & 56.7 & 3.5 & 40.8 & 8.9 & 43.5 \\
\hline DRGI & -0.8 & -3.3 & 11.1 & -14.8 & 9.3 & -15.8 & 0.0 \\
\hline HIEDM & 2.6 & 10.6 & 1.7 & 18.1 & 5.8 & 9.5 & 7.0 \\
\hline HIEDF & 1.0 & 5.4 & 0.5 & 15.7 & 4.1 & 5.6 & 4.2 \\
\hline DRG2 & 38.2 & 35.1 & 54.1 & 7.2 & 23.5 & 32.2 & 33.9 \\
\hline URB & 22.2 & 46.9 & 32.9 & 64.3 & 29.0 & 72.5 & 38.0 \\
\hline AGR & 58.8 & 30.1 & 47.8 & 18.9 & 59.8 & 9.0 & 43.5 \\
\hline TRAD & 11.6 & 12.1 & 15.3 & 16.6 & 12.8 & 15.8 & 13.1 \\
\hline MUSLIM & 84.3 & 10.5 & 32.1 & 4.5 & 31.8 & 4.3 & 36.7 \\
\hline CHRISTIAN & II.5 & 80.7 & 44.3 & 84.7 & 67.4 & 56.6 & 54.3 \\
\hline ANIMIST & 2.9 & 5.7 & 12.6 & 0.6 & 0.3 & 25.8 & 5.5 \\
\hline NNUC & 1.2 & 7.7 & 4.0 & 8.8 & 5.4 & 8.9 & 5.2 \\
\hline ONEP & 6.3 & 25.7 & 12.5 & 24.7 & 19.7 & 35.5 & 18.2 \\
\hline $\mathrm{CONI}$ & 43.1 & 35.2 & 34.3 & 47.6 & 45.6 & 19.3 & 39.2 \\
\hline POL & 34.1 & 7.3 & 24.9 & 2.7 & 1.2 & 1.1 & 14.9 \\
\hline EXT & 15.3 & 24.0 & 24.2 & 16.3 & 28.2 & 35.1 & 22.5 \\
\hline NCONV & 7.3 & 20.4 & 10.6 & 17.6 & 11.7 & 22.4 & 13.9 \\
\hline PLURF & 9.5 & 14.9 & 18.1 & 6.1 & 23.2 & 12.3 & 14.6 \\
\hline WIDOVED & 1.0 & 3.3 & 3.3 & 3.2 & 3.5 & 4.4 & 2.8 \\
\hline DIVORCED & 0.6 & 1.1 & 2.2 & 0.8 & 5.7 & 0.6 & 1.9 \\
\hline $\mathrm{FH}$ & 7.0 & 31.4 & 15.3 & 31.1 & 27.1 & 44.8 & 22.7 \\
\hline FSOL & 0.3 & 2.2 & 0.7 & 3.9 & 1.4 & 1.6 & 1.4 \\
\hline$M<25 M$ & 30.1 & 17.3 & 34.0 & 8.3 & 35.9 & 38.1 & 26.7 \\
\hline $\mathrm{M}<20 \mathrm{~F}$ & 47.1 & 12.6 & 39.2 & 5.9 & 29.5 & 21.9 & 28.2 \\
\hline CEB2 & 1.7 & 1.0 & 1.8 & 0.6 & 1.3 & 1.2 & 1.3 \\
\hline CEB3 & 3.3 & 2.2 & 3.5 & 1.7 & 2.7 & 2.0 & 2.7 \\
\hline CEB4 & 4.7 & 3.5 & 4.9 & 2.9 & 4.2 & 2.7 & 4.0 \\
\hline No. of ethnic groups & 10 & 5 & 11 & 3 & 7 & 2 & 38 \\
\hline
\end{tabular}

Cluster 4 comprises only three ethnic groups: Yoruba and Igbo/lbo (Nigeria), and Kamba (Kenya). This cluster presents the largest percentages of the conjugal households $(47.6 \%)$. Also, the no-nuclear households and the proportion of women among solitaires reach maximum spread. Early marriage is rare for men and women, and fertility levels are low. The spread of illiteracy is very low for both genders, and the proportion of the most educated people is the highest, with slight difference between the two genders. This group also shows a very high (the second among the clusters) level of urbanization and the highest quota of Christians (84.7\%).

Cluster 5 includes seven ethnic groups: all selected ethnic groups of Ethiopia and Zambia, and Emakhuwa (Mozambique). It is characterized by the 
lowest percentage (I.2\%) of polygenic households, as is cluster $6(1.1 \%)$; however, it presents a very large proportion of conjugal households (45.6\%, compared to $19.3 \%$ in cluster 6 ). This cluster shows low levels of urbanization and of highly educated people (especially among women) and shows the highest quota of agricultural workers. Family behaviours are characterized by early marriage for the two genders and by high fertility.

Cluster 6 comprises only two ethnic groups: Português and Xichangana (Mozambique). The conjugal households are less frequent here than elsewhere. The living arrangements are characterized by the maximum diffusion of one-parent, no-nuclear and extended households and also by the strong presence of female-headed households. Consequently, the conjugal households are less frequent than in the other clusters, as is polygyny. The level of urbanization and the percentage of Animism are the highest, and the fertility levels are the lowest. The proportion of illiteracy is low for both genders.

\section{Discussion}

HI: Is a significant nuclearization process, expressed by a growing incidence of household biological nucleus, taking place in sub-Saharan Africa? Is this nuclearization part of an increasing diversification of living arrangements and of a strengthening of new family forms?

A process of erosion of the traditional family system seems to have really begun in sub-Saharan Africa. One-parent and conjugal households are increasing over time, and the proportion of women living in polygynous households is reducing in all considered countries. These results can be considered as indicators of nuclearization, in the hypothesis that it measures the reduction of extended household patterns. However, the process of nuclearization is still not completely observable both in some rural areas and in specific ethnic groups (see clusters I and 3). Moreover, the process of urbanization is undoubtedly characterized by the spread of individual family forms (no-nuclear and oneparent households), even if it has also led, in some cases, to a decrease (perhaps transitory) of the nuclearization. According to the literature (Locoh, 1995; Cordell and Piché, 1995), the results of this study show an increase in female-headed households over time in urban contexts and an incidence of extended households more in urban than in rural areas. These patterns may be just a temporary arrangement adopted by families confronted with urbanization and not a defined trend that will remain stable over time. It was noted, in particular, that the offering of hospitality to relatives external to the 4269 household is a custom of the better off families, which are more frequently found in urban areas (Farina et al., 200I). However, the results suggest that, in many cases, extended households still represent networks of kinship relations, which are still capable of efficient forms of solidarity. If this suggestion reflects the reality, it could be argued that extended households are actually playing an important role in determining the forms of adjustment produced by socio-economic evolution process.

These outcomes support the $\mathrm{HI}$ hypothesis, due to empirical evidences of different living arrangements and new family forms. Nuclearization process is undoubtedly taking place, but it is part of a more complex 'systemic' dynamic.

Living arrangements in sub-Saharan contexts do not completely reflect the classical theory according to which demographic transition produces a growing frequency of the nuclear households (Notestein, 1953; Caldwell, 1976). However, the classical theory is not definitively rejected. Socio-economic evolution process in sub-Saharian countries plays a important role in shaping living arrangements, but family changes will probably also follow original paths that are specific to different ethnic and social groups.

$\mathrm{H}$ 2: Is there one living arrangement pattern that prevails among the others in the sub-Saharan countries?

Each observed country presents considerable rural/urban and ethnic differentials not always strictly linked to socio-economic factors. Moreover, the three nuclear household patterns (extended, conjugal and one-parent) do not have a clear territorial collocation, and they are not connected in a simple way to the development degree of demographic and socio-economic contexts.

Thus, not only must the existence of a single living arrangement pattern in sub-Saharan Africa be excluded (due to the considerable variability of family systems from one country to another), but also it is not even possible to propose general patterns for large geographical regions.

In effect, the factor analysis fully highlights the heterogeneity within each country and among ethnic groups. These results confirm the previously quoted researches that underlined the presence in the subcontinent of a process of growing variability of living arrangements, rather than the existence of a prevalent family pattern.

$\mathrm{H} 3$ : Is it possible to synthesize the variety of the living arrangements by ethnic groups according to linked socio-demographic, cultural and behavioral characteristics?

Living arrangements in the selected countries follow original paths that also differ according to 
ethnic and social groups. Ethnic background is confirmed as an extremely valid interpretative key, which should accompany other socio-demographic characteristics (i.e., urban/rural residence, literacy and religion). The suggestion derived from the clusterization is that each ethnic group has a coherent body of norms that are still capable of guiding individual behaviour in such a way that, on an aggregate level, the imprint of the basic culture is evident independently of circumstances of great weight and significance such as residence, religious affiliation and educational level.

\section{Conclusion}

In sum, a great heterogeneity in household patterns was highlighted. However, certain analogies can be found that reflect similarities of historical and cultural backgrounds, levels of development and - only in some cases - geographical proximity.

The family transition in sub-Saharan Africa is due to different reasons, among which are social and economic conditions such as increases in education levels, in female labour force participation and/or in internal and international migration (Odimegwu et al., 2017).

Some authors have demonstrated that a reduced family size alleviates some of the resource constraints that may impoverish its members (Lachaud et al., 2014). It has also been highlighted that monogamy has the advantage of making more financial resources available for the members of the household, especially for healthy childbearing (Omariba and Boyle, 2007).

In this context, national governments should develop and implement family policies that can raise the wellbeing of the emerging family models. According to scholars, policies that improve women's access to education favour the achievement of important results, such as women's empowerment, delayed marriages and fertility decline. In particular, it was noted that promoting women's empowerment is important since it is essential for the general development of the population (e.g., Duflo, 2012; Jah, 20।4; Larsson and Stanfors, 20I4).

Nevertheless, many countries in Africa do not have explicit family policies. In most countries, national population policies consider family issues only in order to reduce fertility (Odimegwu et al., 2017).

Conversely, few national documents (e.g., the 'White Paper' on families in South Africa) consider the family crucial to the development process and aim to frame this issue into wide policy making initiatives, in order to favour family wellbeing, socioeconomic development and the alleviation of poverty. In this perspective, to realize family policies should give households the chance to be able to provide care and economic, material, psychological and affective support for their members (Department of Social Development, 2012).

Obviously, family policies have to be based on a deep understanding of the evolution of the different living arrangements in sub-Saharan Africa. The persisting and significant differentials among observed countries and ethnic groups confirm that deep and specific investigations in this direction are needed to provide interpretative issues and operative solutions that are closely linked to the cultural contexts and lifestyles of the peoples concerned (Kreager, 1993; Bosede et al., 2017). It is crucial that researchers integrate this knowledge and interpret it in the perspective of the existing interrelations between the family behaviour of the different ethnic groups and the socio-economic evolution process.

\section{Note}

ILaslett (1972) classified 'enlarged families' in two categories: extended (lineally) and expanded (laterally). Many authors, however, use the term 'extended families' to indicate both categories, as a synonym for 'enlarged families'. The latter criterion is followed here.

\section{Acknowledgements}

This article originates, using updated data and partly different methods, from a previous analysis conducted jointly with Dionisia Maffioli and takes suggestions from her innovative studies on the topic of African households. The authors are grateful to Dionisia Maffioli for her co-authorship in the previous published research and for her helpful suggestions in the realization of this article.

Author/s Guarantee Form: Authors declare that all named authors have contributed sufficiently to the work submitted and that the content of the manuscript has never been previously published.

\section{References}

Adepoju, A. and Mbugua, W. 1997. "The African family: an overview of changing forms", in Adepoju, A. (ed), Family, Population and Development in Africa, London and New Jersey: Zed Books: 4I-59.

Bledsoe, C. H. and Pison, G.1997. Nuptiality in subSaharan Africa, Oxford: Clarendon Press.

Banda, P.C., Ntoimo, L.F., and Olamijuwon, E.O. 2017. "Living arrangements and nutritional status of under-five children in Sub-Saharan Africa". African Population Studies, 3I (I): 3639-3649.

Bosede, O.O., Olusina, S.B., Joseph, A.K. and Bola, L.S. 2017. "Family type and ethnic differences in 
lifetime fertility in selected West African countries", African Population Studies, 3I(I): 3586-360I.

Bongaarts, J. 2006. "The Causes of stalling Fertility Transitions", Studies in Family Planning, 37(I): I16.

Bongaarts, J. and Casterline, J. 20I3. "Fertility Transition: Is sub-Saharan Africa different?", Population and Development Review, 38(I): 153168.

Caldwell, J. C. 1976. "Toward a Restatement Demographic Transition Theory", Population and Development Review, 2(3/4): 32I-366.

Caldwell, J. C. and Caldwell P. 1987. "The cultural context of high fertility in sub-Saharan Africa", Population and Development Review, 13(3): 409437.

Caldwell, J.C., Orubuloye I.O. and Caldwell P. 1992. "A new type of fertility transition in Africa", Population and Development Review, I8(2): 21 I242.

Cordell, D. and Victor, P. 1995. "Histoire de la famille en Afrique: au delà de la fabrication de modèles", Communication au Séminaire International sur Ménage et famille en Afrique: bilan, enjeux et perspectives de la recherche, Lomé, 4-9 Décembre.

de Amorim, R.C. 2015. "Feature Relevance in Ward's Hierarchical Clustering Using the LP Norm", Journal of Classification, 32(I): 46-62.

Department of Social Development. 2012. White paper on families in South Africa, Department of Social Development, Republic of South Africa.

DHS. 1996. Sampling Manual. Phase III. Basic Documentation-6. Calverton, Maryland: Macro International Inc.

Eriksen, T.H. 1993. Ethnicity and Nationalism, First Edition, London: Pluto Press.

Farina, P., Gurmu, E., Hasen, A. and Maffioli, D. 200I. "Fertility and Family Change in Ethiopia", Rome, Italy: Central Statistical Authority (CSA), National Research Council (Irp-Cnr).

Gage, A. J. 1997. 'Women's and men's status in African families: Continuity, evolution and possible revolutions", proceedings of the XXIII IUSSP International Population Conference, Bejing, China, II-I7 October.

Garenne, M. 2004. "Age at marriage and modernization in sub-Saharan Africa", Southern African Journal of Demography, 9(2): 57-77.

Garenne, M and Zwang, J. 2006. "Premarital fertility and ethnicity in Africa", DHS Comparative Reports, No. 13, Macro International Inc., Calverton, Maryland, USA.

Jah, F. 20I4. "The Incipient Fertility Transition and Women's Labor Force Participation in Sub-
Saharan Africa, 199|-2005: Evidence From the Demographic and Health Surveys". African Population Studies, 28(2): I I03-I I I8.

Kreager, P. 1993. "Anthropological demography and the limits of diffusionism", Proceedings of the XXII IUSSP Population Conference, Montreal, Canada, 24 August-I September.

Hayase, Y. and Liaw, K. 1997. "Factors on polygamy in sub-Saharan Africa findings based on the demographic and health surveys", The Developing Economies, 35(3): 293-327.

Lachaud, J., LeGrand, T., Adjiwanou, V. and Kobiané, J. 20I4. "Family size and intra-family inequalities in education in Ouagadougou", Demographic Research, 3I(9): |455- |476.

Larsson, C., and Stanfors, M. 20I4. "Women's Education, Empowerment, and Contraceptive Use in sub-Saharan Africa: Findings from Recent Demographic and Health Surveys". African Population Studies, 28(2): 1022-1034.

Laslett, P. 1972. Household and Family in the Past Time, London: Cambridge University Press.

Locoh, T. 1995, "Familles africaines, population et qualité de vie", Les Dossiers du CEPED, 3I, Paris.

Maffioli, D. 2003. "La famiglia africana fra tradizione e mutamento", Annali del Dipartimento di Statistica, Università degli Studi di Bari, 2: 169-222.

Maffioli, D., Dell'Atti, A., Mingolla, G. and Sacco, P. 2006. "The impact of urbanization on the traditional family systems in Africa", Annali del Dipartimento di Scienze Statistiche, Università degli Studi di Bari, 5: 277-336.

Mberu, B. 2007. "Household structure and living conditions in Nigeria", Journal of Marriage and the Family, 69(2): 5 I 3-527

Moore, E. and Govender, J. 2013. "Marriage and Cohabitation in South Africa: An Enriching Explanation?", Joumal of Comparative Family Studies, 44(5): 623-640.

Nyauchi, B. and Omedi, G. 2014. "Determinants of Unmet Need for Family Planning among Women in Rural Kenya". African Population Studies, 28(2): 999-1008.

Notestein, F.W. 1953. "Economic problems of population changes", in Proceedings of the 8th International Conference of Agricultural Economists, London: Oxford University Press: 1518.

Odimegwu, C. and Kekovole, J. (eds) 2014. Continuity and change in sub-Saharan African demography, New York, USA: Routledge.

Odimegwu, C., De-Wet, N., Adedini, S.A., Nzimande, N., Appunni, S., Hochfeld, T. and Dube, T. 2017. "Family Demography in subSaharan Africa: A Systematic Review of Family 
Research", African Population Studies, 3I(I): 3528-3572.

Omariba, W.R. and Boyle, M.H. 2007. "Family structure and child mortality in Sub-Saharan Africa : Cross-national effects of polygyny", Journal of Marriage and Family, 69: 528-543.

Ruhiiga, T.M. 2014. "Urbanisation in South Africa: a critical review of policy, planning and practice", African Population Studies, 28(I):6 1 0:622.

Sellier, J. 2003. Atlas des peuples d'Afrique, Paris: La Découverte.

Udjo, E.O. 2014. "Estimating demographic parameters from the 20II South Africa population census”, African Population Studies, 28(I): 564578.

USAID. 2005. A focus on gender. Collected papers on gender using DHS data, Calverton, Maryland, USA: ORC Macro.

Vignikin, K. 1997. "Structures familiales en Afrique et conséquences démographiques et socioeconomiques", Proceedings of the XXIII IUSSP International Population Conference, Bejing, China, II-I7 October.

Ward, J. H., Jr. 1963. "Hierarchical Grouping to Optimize an Objective Function", Journal of the American Statistical Association, 58: 236-244. 